\title{
No Solar Signal in Temperature Proxies from Antarctica
}

\author{
Maxim Ogurtsov1,2, Markus Lindholm³, Risto Jalkanen'3, Svetlana Veretenenko1,4 \\ ${ }^{1}$ A.F. Ioffe Physico-Technical Institute, St. Petersburg, Russia \\ ${ }^{2}$ Central Astronomical Observatory at Pulkovo, Pulkovo, Russia \\ ${ }^{3}$ Natural Resources Institute Finland (Luke), Rovaniemi, Finla \\ ${ }^{4}$ St. Petersburg State University, St. Petersburg, Russia \\ Email: maxim.ogurtsov@mail.ioffe.ru
}

Received 17 July 2015; accepted 6 October 2015; published 9 October 2015

Copyright (C) 2015 by authors and Scientific Research Publishing Inc.

This work is licensed under the Creative Commons Attribution International License (CC BY).

http://creativecommons.org/licenses/by/4.0/

(c) (i) Open Access

\section{Abstract}

We analyzed a number of Antarctic climatic proxies including: 1) an annual proxy covering the time interval 1800-2003, 2) four low-resolution (tens to hundreds of years) ice core records covering the last 242,000 years. The main goal of the work was to search for traces of solar influence on Antarctic climate. Both Fourier and wavelet approaches were used in the statistical analyses. We found no evident fingerprints of solar cycles of Schwabe (ca 11 years), Hale (ca 22 years), Gleissberg (century-scale) or Hallstatt (ca 2000 years). Instead a strong variation with period ca $9800-11,600$ years is present in the long temperature proxies during the last 242,000 years. It was shown that this variation likely was the result of varying $\mathrm{CO}_{2}$ concentration in the atmosphere, although some solar influence cannot be fully excluded. No features of a quasi 10,000 year variation were found in the Greenland $\delta^{18} 0$ record. The results show that solar-climatic relationship in Antarctica is weaker than in the high-latitude areas of the Northern Hemisphere.

\section{Keywords}

Solar Activity, Paleoclimatiolgy

\section{Introduction}

The enduring question of the existence of a relationship between solar activity and terrestrial climate and its probable physical mechanism is more important than ever in solar-terrestrial physics. Many modern studies have focused on the effect of solar activity on climate-see e.g. De Jager [1], Gray et al. [2] (2010), Lockwood [3], Douglass and Knox [4], Adolphi et al. [23]. Jiang et al. [5] found apparent correlation between changes in sea 
surface temperature in the North Atlantic and variations in the Sun's activity during the last 4000 years over time scales from hundreds of years down to periods of 10 - 20 years. Plausible evidence for century-scale correlation between the Sun's activity and summer temperatures of high-latitude regions of the Northern Hemisphere was obtained by Ogurtsov et al. [6]. Solar influence on climate was found to be more evident over Northern Fennoscandia than elsewhere [7] [8]. High latitudes are areas most suitable for studies of the solar-climate links since: 1) penetration of high-energy solar and cosmic particles into the atmosphere is facilitated over this region; 2) the region is situated far from areas of high volcanic activity, which could obscure solar signal. The Antarctic continent has these same advantages. Temperature proxies, reconstructed temperature variations in Antarctica over different time scales have recently been published. In the present work we analyzed these available indirect records of Antarctic temperatures. We targeted possible fingerprints of centennial-to-millennial scale solar cycles in the Antarctic climate using both wavelet and Fourier approaches and correlation analysis.

\section{Material and Methods}

In this work we used annual reconstruction of Antarctic mean surface temperature for AD 1800-2003 based on stable isotope records from high-resolution ice core records [9]. The reconstruction utilized the following data sets:

a) $\delta^{18} \mathrm{O}$ ice core record from Law Dome $\left(66.78^{\circ} \mathrm{S}, 112.82^{\circ} \mathrm{E}\right.$, elevation $1370 \mathrm{~m}$ a.s.l.) [10];

b) $\delta^{18} \mathrm{O}$ ice core record from Siple Station $\left(75.92^{\circ} \mathrm{S}, 84.10^{\circ} \mathrm{W}\right.$, elevation $1054 \mathrm{~m}$ a.s.l.) [11];

c) $\delta^{18} \mathrm{O}$ ice core record from Dronning Maud Land $\left(\sim 75^{\circ} \mathrm{S}, 0^{\circ} \mathrm{E}\right.$, elevation $2900 \mathrm{~m}$ a.s.l. $)$ [12];

d) $\delta^{18} \mathrm{O}$ ice core record US ITASE $2000-1\left(79.38^{\circ} \mathrm{S}, 111.23^{\circ} \mathrm{W}\right.$, elevation $1791 \mathrm{~m}$ a.s.l.) [13];

e) $\delta$ D ice core record US ITASE $2000-5\left(77.68^{\circ} \mathrm{S}, 123.99^{\circ} \mathrm{W}\right.$, elevation $1828 \mathrm{~m}$ a.s.1.) [13].

Deuterium and $\delta^{18} \mathrm{O}$ content of Antarctic snow is linearly related to the temperature of precipitation site because of fractionation processes [14]. Therefore all the paleorecords may be considered as rather reliable temperature proxies. A generalized Antarctic temperature series is shown in Figure 1.

We also used the long and low-resolution data sets (Figure 2):

a) Deuterium $\delta \mathrm{D}$ and $\mathrm{CO}_{2}$ data from Vostok ice core (78.8 ${ }^{\circ} \mathrm{S}, 106.8^{\circ} \mathrm{E}$, elevation $3488 \mathrm{~m}$ a.s.l.), [14]-[16];

b) Deuterium data from EPICA Dome C (75.06 ${ }^{\circ} \mathrm{S} ; 123.21^{\circ} \mathrm{E}$, elevation $3233 \mathrm{~m}$ a.s.l.) [17];

c) Estimation of temperature at Dome Fuji $\left(77.30^{\circ} \mathrm{S}, 37.30^{\circ} \mathrm{E}\right.$, elevation $3810 \mathrm{~m}$ a.s.l.) [18].

The estimations of Kawamura et al. [18] were made by means of $\delta \mathrm{D}$ and $\delta^{18} \mathrm{O}$ data. Carbon dioxide is a well known greenhouse gas effectively influencing terrestrial climate. All three sites (Vostok, EPICA Dome C and Dome F) are located on the continental part of Antarctica, more than $1000 \mathrm{~km}$ away from the ocean. The above described paleoisotope records span time intervals up to 800,000 years before present. Their time resolution reaches only few hundreds of years or even merely 35 - 60 years during some time intervals [19]. This is enough for a search of time variations with periods of a few millennia. These time series have successfully been used for timing glacial-interglacial variations [20] as well as detecting climatic periodicities connected with astronomical cycles - changes in eccentricity (100,000 years), obliquity (41,000 years), and precession (19,000 - 23,000 years) [21]. We interpolated all four time series by 50 years and used time interval up to 242,000 BP in order to match all the data sets. Long-term trends—22 points (1100 years) averages - were then removed from the interpolated data sets, since such strong variations are plausibly caused by glacial-interglacial and astronomic cycles. The detailed and continuous high-frequency profiles are shown as functions of time in Figure 3.

We used radiocarbon data after Reimer et al. [22] as a long-term solar proxy. This time series covers the last 50,000 years as shown in Figure 4.

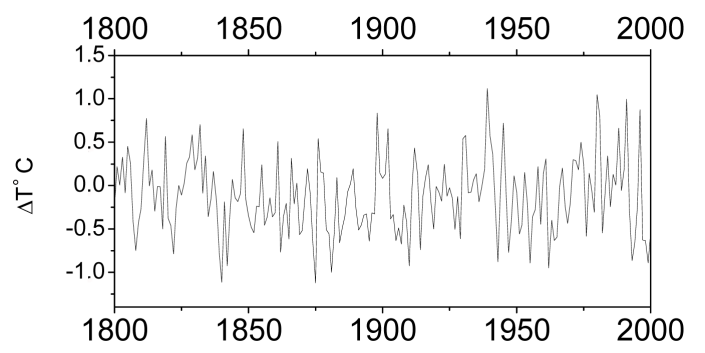

Figure 1. Annual Antarctic temperature [9]. 


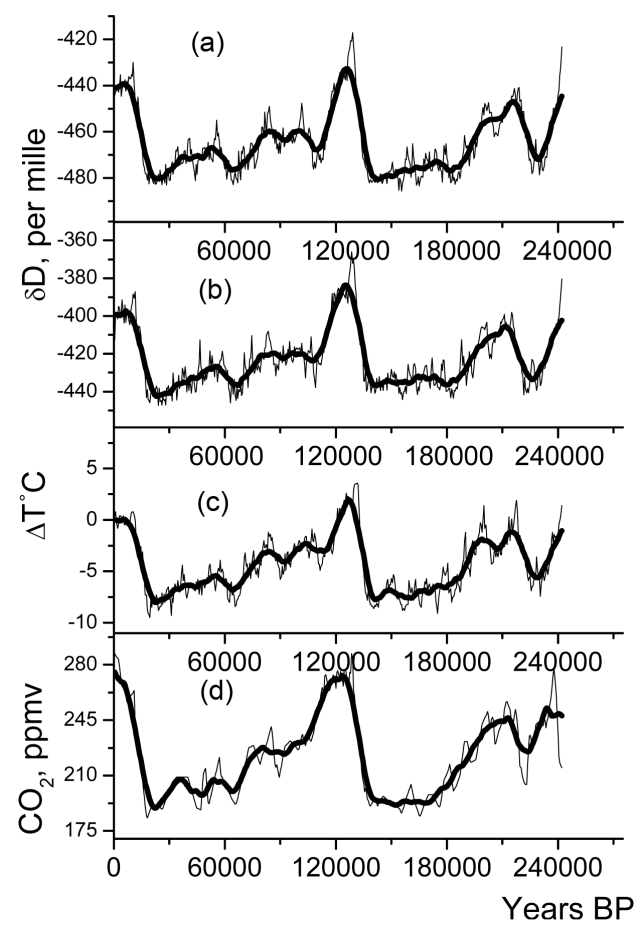

Figure 2. Long Antarctic data sets. (a) Deuterium concentration measured in Vostok core; (b) Deuterium concentration measured in EPICA Dome C core; (c) Estimations of temperature at Dome Fuji core; (d) $\mathrm{CO}_{2}$ concentration measured in Vostok core. All the time series were interpolated by 50 years. Thick lines-long-term tendencies (22 point averages).

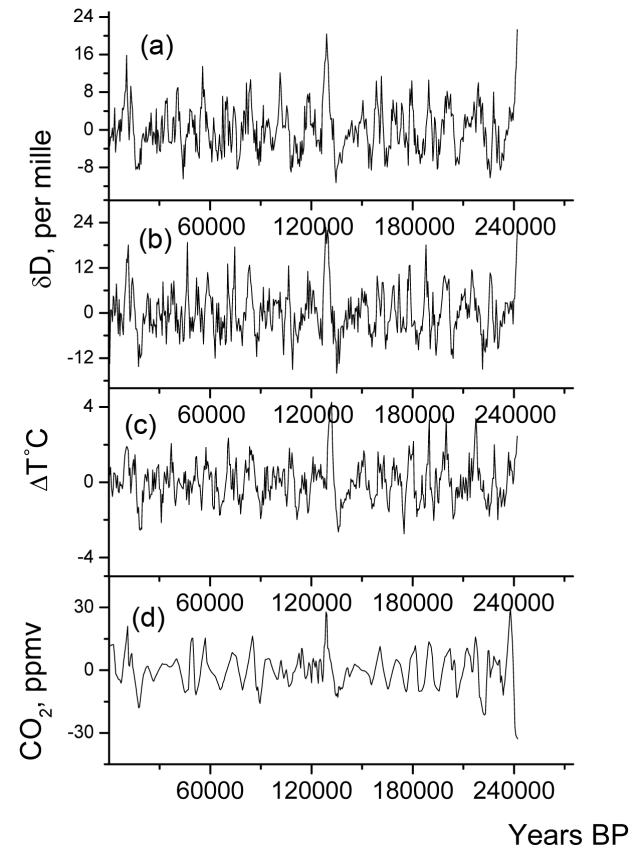

Figure 3. Time series after removing long-term trends. (a) Deuterium measured in Vostok core; (b) Deuterium measured in EPICA Dome C core; (c) Estimations of temperature at Dome Fuji core; (d) $\mathrm{CO}_{2}$ measured in Vostok core. 


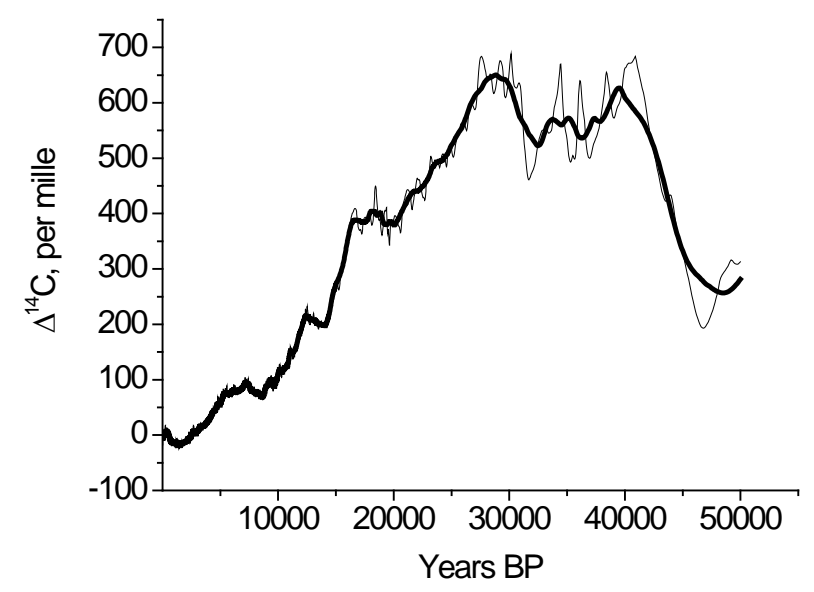

Figure 4. Concentration of radiocarbon in terrestrial atmosphere after Reimer et al. [22]. Thin line-raw data, thick line-1100 year average.

\section{Results and Discussion}

Both Fourier and wavelet approaches were applied in spectral analyses. The main shortcoming of the Fourier method there is assumption of stationarity of the process. In case of a nonstationary data set (such as the bulk of climatic series) the Fourier transform can evaluate only the average power at a given frequency and it is impossible to trace the variation of spectral content in time. The main advantage of the wavelet transform over the Fourier transform is that the analyzed signal here is decomposed not to infinite sinusoidal harmonics but to a number of orthogonal waves of solyton type. These waves are called wavelets and they are well localized both in frequency and in time, while Fourier harmonics are localized only in frequency. Wavelet and Fourier spectra of the annual reconstruction of Antarctic temperature during AD 1800-2000 [9] are illustrated in Figure 5.

According to Figure 5 the only periodicity in temperature that can be related to changing solar activity is the 14.3 year variation. A century-type variation, which might be attributed to the solar cycle of Gleissberg, is very weak. Moreover, there is no correlation between Antarctic temperature and sunspot number. Thus not even the 14.3 year periodicity likely has solar origin.

Wavelet and Fourier spectra of the 242,000 years long Antarctic ice core records are shown in Figure 6 and Figure 7.

A strong variation with a period of 8900 - 10,040 years is a shared feature in all analyzed time series (Figure 6 and Figure 7). This is also evident in Figure 3. We call this variation a quasi 10 kA periodicity. This periodicity results in correlation between higher-frequency parts of the paleorecords-see Table 1 . The significance of correlations $P_{\text {corr }}$ was estimated statistically including permutation of phases of Fourier transform. In all cases the maximum correlation coefficient (Table 1) is reached with zero time shift. Such synchrony shows that the accuracy of dating of the analyzed paleorecords is at least in the range of 50 years. A highly significant linear relationship evidently is a result of the presence of a common component of variability in all the analyzed series.

Cross-wavelet spectra of the four climatic series show peaks at ca 10,000 years. In order to clarify whether this 10,000 year variation is present in cosmic ray intensity we performed Fourier and wavelet analysis of the 50,000 year long radiocarbon record after removing the 1100 year average (see Figure 4). Fourier and MHAT wavelet spectra are shown in Figure 8.

Highly significant peaks at ca 10,000 years, 3571 years and 1851 years can be seen in the Fourier spectrum (Figure 8(c)). Ca 2000 year variation likely is a manifestation of the solar Hallstatt cycle. It is more evident during 32,000 - 40,000 BP-see four distinct details in MHAT wavelet spectrum (Figure 8(b)). The peak at 10,000 years in the Fourier spectrum is created by only one corresponding strong fluctuation at ca 40,000 50,000 years BP. Thus it is hard to speak about 10,000 year periodicity in the ${ }^{14} \mathrm{C}$ data. That is why it is also difficult to relate persistent 10,000 variation to solar-cosmic influence. It is reasonable to assume that the variation in $\mathrm{CO}_{2}$ concentration is responsible for the corresponding temperature variations, although some solar-cosmic influence cannot be fully excluded. We can note also that no signs of Hallsttatt cycle (ca 2000 year) were found in the long Antarctic climatic proxies. In addition no signs of 10,000 year variation were found in Greenland. 

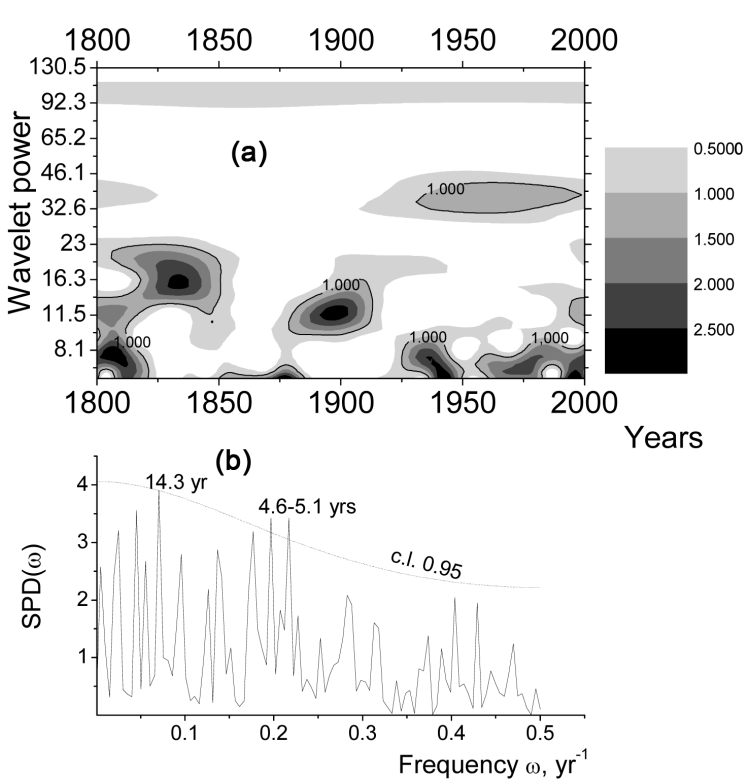

Figure 5. (a) Local wavelet spectrum (basis of Morlet) of Antarctic temperatures reconstructed by Schneider et al. [9]. The spectrum is normalized to 0.99 confidence level; (b) Fourier spectrum of Antarctic temperatures. Dotted line- 0.95 confidence level.

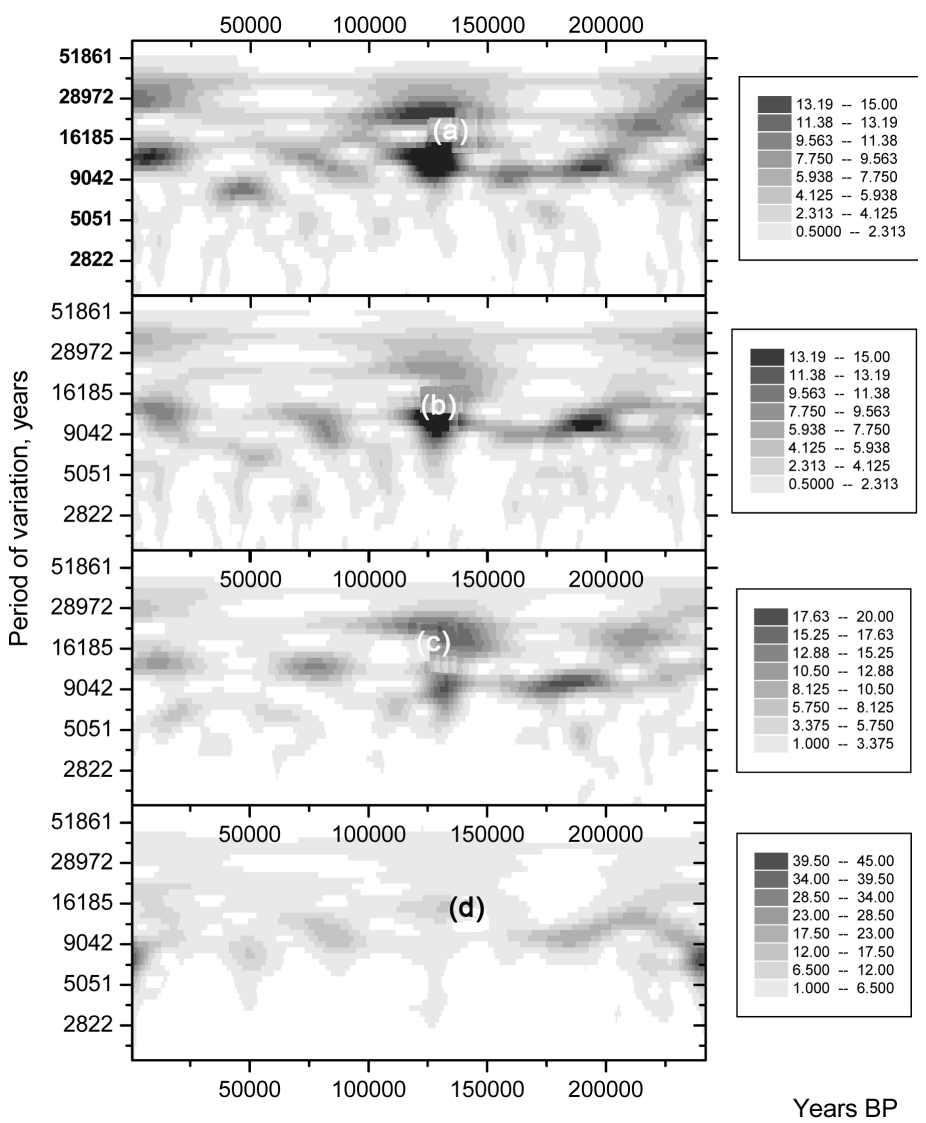

Figure 6. Local wavelet spectra of the detrended time series plotted in Figure 3: (a) Deuterium from Vostok; (b) Deuterium from Epica dome C; (c) Temperature from Dome F; (d) $\mathrm{CO}_{2}$ from Vostok. All spectra were normalized by variance. 


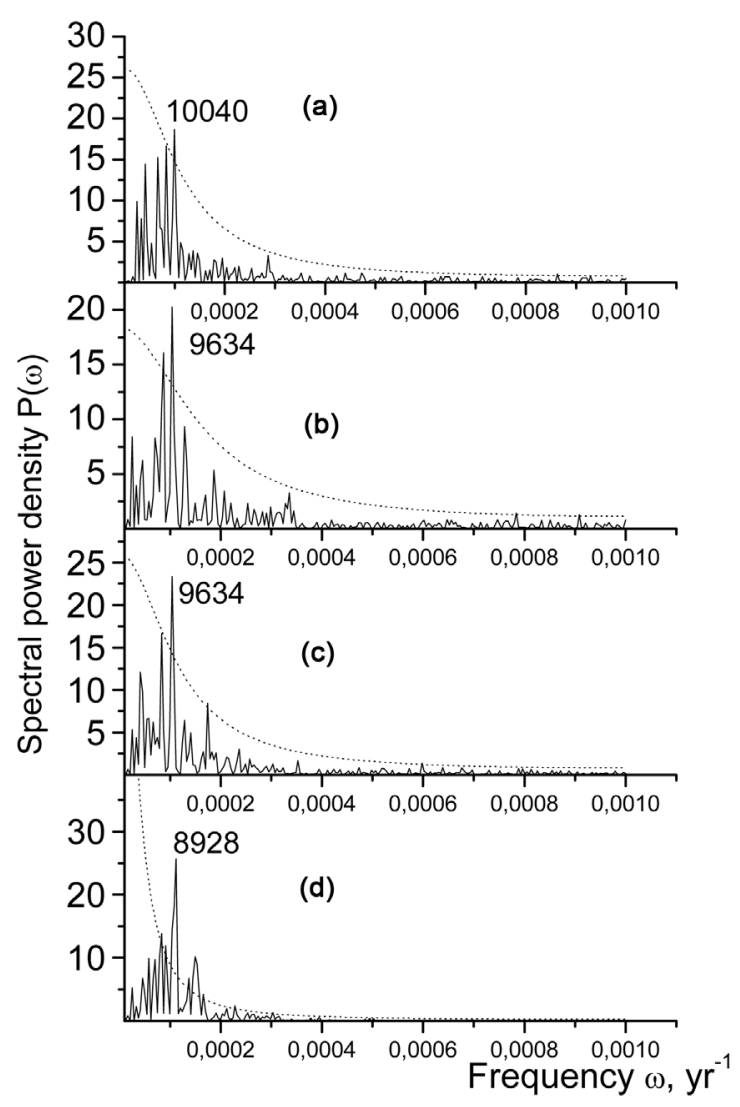

Figure 7. Fourier spectra of the detrended time series plotted in Figure 3: (a) Deuterium from Vostok; (b) Deuterium from Epica dome C; (c) Temperature from Dome F; (d) $\mathrm{CO}_{2}$ from Vostok. Dotted lines—confidence level 0.99.

Table 1. Correlations between the detrended datasets. The significance of correlation is shown in brackets.

\begin{tabular}{ccccc}
\hline & $\delta$ D at Vostok & $\delta$ D at Epica dome C & Temperature at Dome F & $\mathrm{CO}_{2}$ at Vostok \\
\hline$\delta$ D at Vostok & 1.0 & $0.426(>0.99)$ & $0.391(>0.99)$ & $0.367(>0.99)$ \\
$\delta$ D at Epica dome C & $0.426(>0.99)$ & 1.0 & $0.421(>0.99)$ & $0.287(0.99)$ \\
Temperature at Dome F & $0.391(>0.99)$ & $0.421(>0.99)$ & 1.0 & $0.328(>0.99)$ \\
$\mathrm{CO}_{2}$ at Vostok & $0.367(>0.99)$ & $0.287(0.99)$ & $0.328(>0.99)$ & 1.0 \\
\hline
\end{tabular}

This is evidence that this periodicity is not a global scale cycle but a local feature of continental Antarctic climate.

\section{Conclusion}

Analysis of the annual Antarctic temperature proxy spanning AD 1800-2003, indicates no fingerprints of the influence of solar cycles of Schwabe (ca 11 year), Hale (ca 22 year) or Gleissberg (century-scale). In addition, the long Antarctic climatic proxies show no evidence of solar Hallstatt (ca 2000 year) periodiocity. Instead, a strong variation with a period of 9800 - 11,600 years was found in temperature proxies obtained from three continental Antarctic ice cores (Vostok, Dome F, Epica Dome C). The variation was persistent during the last 240,000 years. The same periodicity was also present in $\mathrm{CO}_{2}$ concentration from the Vostok ice core. All four proxies correlate significantly with each other and their cross-wavelet spectra show concentration of variance at ca 10,000 years. We conclude that a long-term variation with a period close to 10,000 years is a common mode of continental Antarctic climate variability. Analysis of radiocarbon record, covering the last 50,000 years, showed that this 


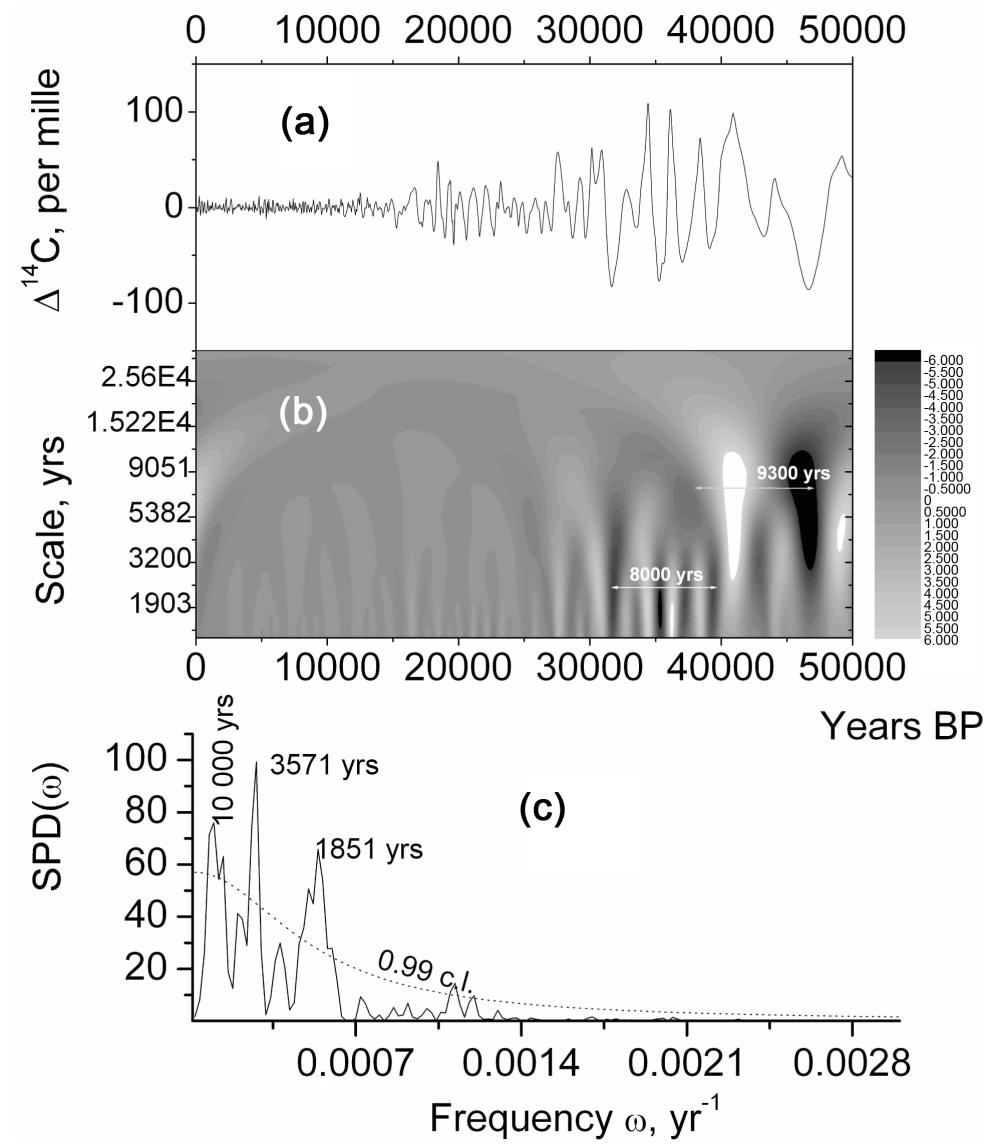

Figure 8. (a) High-frequency part of the radiocarbon record of Reimer et al. [22]; (b) Its local wavelet spectrum (MHAT basis) normalized by variance; (c) Its Fourier spectrum. Dotted line is confidence level 0.99.

time series has variability in Hallstatt (ca 2000 year) frequency band and a strong ca 10,000 year fluctuation in 40,000 - 50,000 BP. Thus, some influence of solar-cosmic factors on the 10,000 variation of continental Antarctic climate cannot be fully excluded. However, taking into consideration that the concentration of carbon dioxide in Vostok core has evident 10,000 year cyclicity which correlates with other climatic series, it is reasonable to assume that the variation in atmospheric $\mathrm{CO}_{2}$ concentration is the cause of climatic 10,000 year periodicity. In any case, actual origins of the here revealed 10,000 year climatic variation need further profound investigation. The present analysis indicates that solar activity probably influences the Antarctic climate less than the high-latitude regions of the Northern Hemisphere. This further testifies that a potential solar-climatic link actually has a strong spatial variability. Further studies are necessary for more decisive conclusions. First of all, we need more high-resolution proxies for Antarctic climate in order to analyze spatial distribution of solar-climate link over the Antarctic continent. Upgrading old and building new long (tens of thousands of years) proxies of solar activity are also crucial tasks with respect to future studies.

\section{Acknowledgements}

M. G. Ogurtsov expresses his thanks to the exchange program between the Russian and Finnish Academies (project No. 16), to the program of the Presidium of RAS No. 22, and to RFBR grants 13-02-00277, 13-0200783 for financial support.

\section{References}

[1] De Jager, C. (2005) Solar Forcing of Climate: Solar Variability. Space Science Reviews, 120, 197-241. http://dx.doi.org/10.1007/s11214-005-7046-5

[2] Gray, L.J., Beer, J., Geller, M., Haigh, J.D., Lockwood, M., Matthes, K., Cubasch, U., Fleitmann, D., Harrison, G., 
Hood, L., Luterbacher, J., Meehl, G.A., Shindell, D., van Geel, B. and White, W. (2010) Solar Influences on Climate. Reviews of Geophysics, 48, Article ID: RG4001. http://dx.doi.org/10.1029/2009RG000282

[3] Lockwood, M. (2010) Solar Change and Climate: An Update in the Light of the Current Exceptional Solar Minimum. Proceedings of the Royal Society A, 466, 303-329. http://dx.doi.org/10.1098/rspa.2009.0519

[4] Douglass, D.H. and Knox, R.S. (2015) The Sun Is the Climate Pacemaker II. Global Ocean Temperatures. Physics Letters A, 379, 830-834.

[5] Jiang, H., Muscheler, R., Bjorck, S., Seidenkrantz, M.-S., et al. (2015) Solar Forcing of Holocene Summer Sea-Surface Temperatures in the Northern North Atlantic. Geology, 43, 203-206. http://dx.doi.org/10.1130/g36377.1

[6] Ogurtsov, M., Lindholm, M., Jalkanen, R. and Veretenenko, S.V. (2015) Evidence for the Gleissberg Solar Cycle at the High-Latitudes of the Northern Hemisphere. Advances in Space Research, 55, 1285-1290. http://dx.doi.org/10.1016/j.asr.2014.11.031

[7] Ogurtsov, M.G., Kocharov, G.E., Lindholm, M., et al. (2002) Evidence of Solar Variation in Tree-Ring-Based Climate Reconstructions. Solar Physics, 205, 403-417. http://dx.doi.org/10.1023/A:1014277121166

[8] Ogurtsov, M., Lindholm, M., Jalkanen, R. and Veretenenko, S.V. (2013) New Evidence of Solar Variation in Temperature Proxies from Northern Fennoscandia. Advances in Space Research, 52, 1647-1654. http://dx.doi.org/10.1016/j.asr.2013.07.039

[9] Schneider, D.P., Steig, E.J., van Ommen, T.D., et al. (2006) Antarctic Temperatures over the Past Two Centuries from Ice Cores. Geophysical Research Letters, 33, Article ID: L16707. http://dx.doi.org/10.1029/2006gl027057

[10] van Ommen, T.D. and Morgan, V. (1997) Calibrating the Ice Core Paleothermometer Using Seasonality. Journal of Geophysical Research, 102, 9351-9357. http://dx.doi.org/10.1029/96JD04014

[11] Mosley-Thompson, E., Thompson, L.G., Grootes, P.M. and Gunderstrup, N. (1990) Little Ice Age (Neoglacial) Paleo Environmental Conditions at Siple Station, Antarctica. Annals of Glaciology, 14, 199-204.

[12] Graf, W., Oester, H., Reinwarth, O., et al. (2002) Stable Isotope Records from Dronning Maud Land, Antarctica. Annals of Glaciology, 35, 195-201. http://dx.doi.org/10.3189/172756402781816492

[13] Steig, E.J., Mayewski, P., Dixon, D., et al. (2005) High-Resolution Ice Cores from US-ITASE (West Antarctica): Development and Validation of Chronologies and Determination of Precision and Accuracy. Annals of Glaciology, 41, 77-84. http://dx.doi.org/10.3189/172756405781813311

[14] Petit, J.R., Jouzel, J., Raynaud, D., et al. (1999) Climate and Atmospheric History of the Past 420,000 Years from the Vostok Ice Core, Antarctica. Science, 399, 429-435.

[15] Lorius, C., Jouzel, J., Ritz, C., et al. (1985) A 150,000-Year Climatic Record from Antarctic Ice. Nature, 316, $591-596$. http://dx.doi.org/10.1038/316591a0

[16] Sowers, T., Bender, M., Labeyrie, L.D., et al. (1993) 135000 Year Vostok-SPECMAP Common Temporal Framework. Paleoceanography, 8, 737-766. http://dx.doi.org/10.1029/93PA02328

[17] Jouzel, J., Masson-Delmotte, V., Cattani, O., et al. (2007) Orbital and Millennial Antarctic Climate Variability over the Past 800,000 Years. Science, 317, 793-797. http://dx.doi.org/10.1126/science.1141038

[18] Kawamura, K., Parrenin, F., Lisiecki, L., et al. (2007) Northern Hemisphere Forcing of Climatic Cycles in Antarctica over the Past 360,000 Years. Nature, 448, 912-916. http://dx.doi.org/10.1038/nature06015

[19] Pol, V., Debret, M., Masson-Delmotte, V., et al. (2011) Links between MIS 11 Millennial to Sub-Millennial Climate Variability and Long Term Trends as Revealed by New High Resolution EPICA Dome C Deuterium Data-A Comparison with the Holocene. Climate of the Past, 7, 437. http://dx.doi.org/10.5194/cp-7-437-2011

[20] Waelbroeck, C., Jouzel, J., Labeyrie, L., et al. (1995) Comparing the Vostok Ice Deuterium Record and Series from Southern Ocean Core MD 88-770 over the Last Two Glacial-Interglacial Cycles. Climatic Dynamics, 12, 113-123. http://dx.doi.org/10.1007/BF00223724

[21] Shackleton, N.J. (2000) The 100,000-Year Ice-Age Cycle Identified and Found to Lag Temperature, Carbon Dioxide, and Orbital Eccentricity. Science, 289, 1897-1901. http://dx.doi.org/10.1126/science.289.5486.1897

[22] Reimer, P.J., Baillie, M.G.L., Bard, E., et al. (2009) INTCAL09 and MARINE09 Radiocarbon Age Calibration Curves, 0-50,000 Years Cal BP. Radiocarbon, 51, 1111-1150.

[23] Adolphi, F., Muscheler, R., Svensson, A., et al. (2014) Persistent Link between Solar Activity and Greenland Climate during the Last Glacial Maximum. Nature Geoscience, 7, 662-666. http://dx.doi.org/10.1038/ngeo2225 